\title{
Rhetorical questions or rhetorical uses of questions?
}

\author{
Džemal Špago \\ Džemal Bijedić University of Mostar
}

\begin{abstract}
This paper aims to explore whether some rhetorical questions contain certain linguistic elements or forms which would differentiate them from answer-eliciting and action-eliciting questions, and thereby hint at their rhetorical nature even outside the context. Namely, despite the fact that the same questions can be rhetorical in one context, and answer-eliciting in another, some of them are more likely to be associated with rhetorical or non-rhetorical use. The analysis is based on extensive data (over 1200 examples of rhetorical questions taken from 30 plays by two British and two American writers), and the results are expected to give an insight into whether we can talk about rhetorical questions or just a rhetorical use of questions.
\end{abstract}

Key words: rhetorical question; indicators of rhetorical questions; polarity items; semantic incompatibility.

\section{Introduction}

According to Athanasiadou (1991), questions can be classified into four categories based on their function in communication and intentions of speakers: informationseeking questions, rhetorical questions (henceforth, $\mathrm{RQ}$ ), examination questions and indirect requests. While defining examination questions as those asked in order to test the knowledge of addressees or to interrogate them, and indirect requests as questions intended to urge addressees to do something, she claims that the first two types of questions are in clear opposition. Namely, whereas information-seeking questions are aimed at requesting information, RQs, on the other hand, are not asked in order to get an answer, but instead serve the purpose of providing information. Based on a type of response they initiate, Ilie (1994) classifies questions into three groups: answer-eliciting, action-eliciting, and mental-response eliciting questions, placing RQs into the third group, and claiming that RQs actually require a cognitive response represented by the addressee's acceptance of the answer implied by the speaker. She defines an RQ as: „.... question used as a challenging statement to convey the addresser's commitment to its implicit answer, in order to induce the addressee's mental recognition of its obviousness and the acceptance, verbalized or non-verbalized, of its validity."(Ilie, 1994: 128) 
In any case, RQs differ from answer-eliciting questions, among other things, in that they are intended to convince the addressees to accept the apparently obvious answer implied by the addressor, and not to get a verbalized answer from them. ${ }^{1}$ Furthermore, as Schaffer (2005) shows in her study, RQs are often used as effective and powerful answers to standard questions.

The issue that arises is whether RQs, at least sometimes, have a specific form that differentiates them from other types of questions, or whether we can just talk about a special use of questions whose form is the same as the form of nonrhetorical questions. Our goal in this research was to look for certain forms that could be indicative of RQs, as well as to find out how often they occur.

\section{Background}

Due to their persuasive effect and communicative effectiveness, rhetorical questions are widely used in different languages, different situations, and by different types of language-users. They occur frequently in day-to-day communication, as well as in various specific fields, such as marketing, politics, literature, journalism, etc. They are generally understood as questions that are not meant to be answered, but rather to convey a message that would not be as memorable and as persuasive had it been expressed as a straightforward statement.

One of the most striking characteristics of RQs is that they are used in order to achieve something else other than to elicit an answer. Such questions, in most cases, already imply an answer that seems obvious to both the addressor and the addressee. They have the illocutionary force of a statement of opposite polarity from that of the question (Sadock, 1974; Han, 2002):

Are we going to believe in everything they say? is equivalent to We are not going to believe...; and

Isn't this the only sensible thing to do? is equivalent to This is the only sensible thing to do. ${ }^{2}$

Such implicit statements, presented in the form of questions, are often more powerful and effective, and have more influence on addressees than direct statements (Frank, 1990), which is one of the reasons for the frequent use of RQs in communication.

Another reason for the communicative effectiveness and common usage of RQs is that they can perform a number of different functions in communication, some-

\footnotetext{
1 Although the speaker's intention is not to get a verbalized answer to RQs, addressees sometimes provide it, whether to challenge the implied answer, or because they misinterpret the question as answer-eliciting.

2 However, sometimes the question and the statement it implies have the same polarity: Is the Pope Catholic? is equivalent to Of course the Pope is Catholic.
} 
times even the ones that seem to be conflicting. Namely, while Brown \&Levinson (1987) point out mitigation of criticism in performing face-threatening acts ${ }^{3}$ as a particularly important function of RQs, Frank (1990) notes that RQs can both soften criticism and strengthen assertions, and concludes that the latter is the primary function of such questions. As common functions of RQs Ilie (1994) mentions defending one's own opinion, manipulating and changing the opinion of others, making one's message more memorable, being ironic, etc. According to Gergen (2001), RQs can be a powerful weapon in political speeches. ${ }^{4}$

Schaffer (2005) analyzed RQs which are used as answers to informationeliciting questions, and found out that achieving a humorous effect is often a goal of such RQs:

\section{A: How reliable is he?}

\section{B: How shallow is the ocean? How cold is the Sun? ${ }^{5}$}

These RQs imply obvious answers that the ocean is not shallow and the Sun is not cold, so, by extension, they answer the posed question - the person referred to is not reliable at all. In the above-mentioned example, the goal of the speaker is also to produce a humorous effect, and thereby make his point more memorable and convincing.

When it comes to whether RQs (may) have a distinct form, Ilie (1994) claims that pragmatic factors (and not a specific form) are what differentiates rhetorical from non-rhetorical questions, and that RQs are a special use rather than a special category of questions. Similarly, Jung \& Schrott (2003) state that RQs are neither bound to a specific language nor to specific linguistic structures - whether a question is rhetorical or not depends on the context. ${ }^{6}$ On the other hand, Schmidt-Radefeldt (1977) lists two types of RQs whose form is indicative of their rhetorical nature - autoresponsive RQs (questions that include an answer) and implicative RQs (questions whose answer is obvious even outside the context due to the general knowledge of interlocutors). ${ }^{7}$ Furthermore, Sadock (1974) analysed certain lexical and syntactic elements that can help us determine whether a question is rhetorical or not.

\footnotetext{
${ }^{3}$ Face-threatening acts are those speech acts that can potentially be offensive or embarrassing to interlocutors, such as criticizing, warning, threatening, etc. (see Brown \&Levinson, 1987).

4 Over the years Reagan had shown that asking rhetorical questions could be a powerful weapon with audiences. (Gergen, 2001: 163).

${ }^{5}$ Examples taken from Schaffer (2005: 436).

${ }^{6}$ Jung \& Schrott (2003: 360).

7 Who else burns a cheque if not an idiot? is an example of auto-responsive RQ, and Which reasonable man would vote conservative? is an example of implicative RQ (see Schmidt-Radefeldt, 1977: 383-384).
} 


\section{Data}

The goal of this study was to identify and analyse syntactic and semantic elements that differentiate rhetorical from non-rhetorical questions, as well as to determine their frequency of occurrence. The corpus consisted of 30 plays by two British $(\mathrm{H}$. Pinter and T. Stoppard) and two American playwrights (T. Williams and A. Miller), as plays faithfully simulate real life situations. British and American authors were included in order to pay equal attention to the two main variants of the English language, although our intention was not to look for possible differences between them in regard to RQs. All together, we identified 1205 examples of RQs, ${ }^{8}$ some of them strings of two or more questions. ${ }^{9}$

\section{Results and discussion}

Although context remains the ultimate and the most salient indicator of whether a question is rhetorical or not, some questions tend to be 'more inclined' towards rhetorical or non-rhetorical interpretation. For instance, the question What time is it? will most likely be interpreted as answer-eliciting in almost any context, whereas How can a fool know what's good for him? will hardly ever be understood as an answer-eliciting question. While most questions, unlike the above examples, cannot readily be determined as rhetorical or answer-eliciting, the fact that such questions do exist indicates that some RQs contain certain elements that point at their rhetorical nature.

The results of this study support the view that RQs may contain such elements on syntactic and semantic level. While in reality they are all intertwined and together contribute to rhetorical interpretation of questions, in this paper we analyse them separately for the sake of clarity. Altogether, we identified seven distinct forms which indicate that a question is rhetorical. As shown in Figure 1, out of the total number of RQs found in our corpus, $14 \%$ are realized in one of those forms:

\footnotetext{
${ }^{8}$ Among these, we did not include expository (What can we do? Well, we can...), philosophical (Where do we come from, and where are we going?), nor action-eliciting questions (Can you open the door, please?). We also did not include questions that are used to attract the addressee's attention (You know what I think? I think...), although some authors (Schmidt-Radefeldt, 1977; Athanasiadou, 1991) include them into RQs. ${ }_{9}^{9}$ Strings of RQs are counted as one example (out of 1205 examples, 159 were strings of two or more RQs).
} 


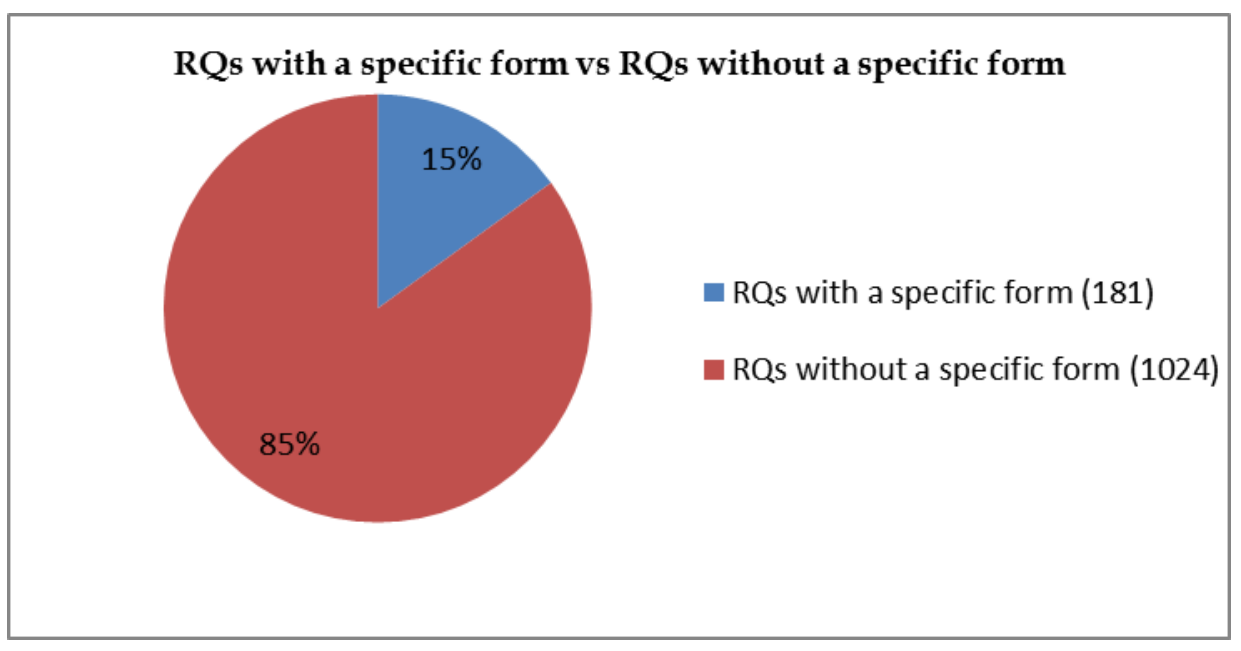

Figure 1: RQs with and without a specific form

\subsection{Syntactic indicators that a question is rhetorical}

Syntactic indicators of the rhetorical nature of a question can be placed into one of the six categories:

- the use of polarity items in questions,

- introducing questions with a lexical item incompatible with asking for information,

- questions accompanied by ridiculous answers,

- questions realized in why + lexical verb form,

- questions incorporated into declarative or imperative sentences, and

- auto-responsive questions.

\subsubsection{Polarity items as markers of $R Q s$}

PIs are lexical units that can only be used in affirmative (positive polarity items PPIs) or negative sentences (negative polarity items - NPIs):

I have some questions. ( $\quad$ ( I don't have some questions.)

I don't have any questions. ( ${ }^{*}$ have any questions.)

There is a distinction between weak PIs (for instance, some and any in the above examples) and strong PIs, which include idiomatic expressions such as lift a finger, budge an inch, etc. (Zwarts, 1996; Han 2002). In regard to questions, the presence of 
strong NPIs is invariably an indicator that the question is rhetorical, no matter what the context is, and regardless of whether it is a wh- or yes-no question:

(1) CHARLEY: Yeah, but there's no bones in a heartburn.

WILLY: What are you talkin' about? Do you know the first thing about it? CHARLEY: Don't get insulted.

(Miller, Death of a Salesman, 48)

(2) HYMAN: Call it hysterical, does that bring you one inch closer to what is driving that woman? (...)

(Miller, Broken Glass, 539)

(3) BERNARD: (...) I can't think of anything more trivial than the speed of light. Quarks, quasars - big bangs, black holes - who gives a shit? (...)

(Stoppard, Arcadia, 52)

However, the results obtained in this study indicate that RQs that include such strong NPIs are extremely rare, since only 5 out of 1205 of RQs from our corpus $(0.4 \%)$ had such form.

As for weak NPIs, the only recurring one in RQs from our corpus was ever. The presence of ever in wh-questions leads us to understand such questions as rhetorical:

(4) HOLGA: But how can one ever be sure of one's good faith?

(Miller, After the Fall, 271)

(5) GIEREK: (...) When did the Party leader ever come to debate with the workers face to face on their ground? (...)

(Stoppard, Squaring the Circle, 197)

Although Han (2002) shows that wh-questions with who that include ever can also be interpreted as answer-eliciting, ${ }^{10}$ they are often interpreted as RQs, which is supported by he results of this study. Namely, examples of such RQs from our corpus can only have rhetorical interpretation:

(6) ALFIERI: Who can ever know what will be discovered?

(Miller, A View from the Bridge, 332)

(7) ROBERTSON: (...) But at the same time they were putting up the Empire State Building, highest in the world. But with whole streets and avenues of empty store who would ever rent space in it?

(Miller, The American Clock, 420)

According to the results that we obtained, RQs with ever incorporated into whquestions are also very rare, since we identified only $10 \mathrm{RQs}$ with such form (0.8\%).

\footnotetext{
${ }^{10}$ Who has ever been to Seoul? can be interpreted as an answer-eliciting or rhetorical question.
} 
Unlike with wh-questions, the presence of ever in yes-no questions does not predetermine if the question is rhetorical or not. Has he ever helped you? can be interpreted as a request for information or as an implicit statement that He has never helped you.

4.1.2. Introducing questions with a lexical item incompatible with asking for information

There are certain words and expressions that are normally used to introduce or modify statements, so, if they precede questions, it is a clear indicator that those questions are rhetorical. We identified $27 \mathrm{RQs}(2.2 \%)$ in our corpus that are introduced with such lexical items incompatible with asking for information. As for single words, they include because and otherwise:

(8) ISABEL: (...) Even if George comes back, he ought not to find me here like a checked package waiting for him to return with the claim check. Because, if you give up your pride, what are you left with, really?

(Williams, Period of Adjustment, 252)

(9) LADY CROOM: Mr Chater, you are a welcome guest at Sidley Park but while you are one, The Castle of Otranto was written by whomsoever I say it was, otherwise what is the point of being a guest or having one? (...)

(Stoppard, Arcadia, 11)

As for expressions, a recurring one that we identified in our corpus is after all, which can also be used in combination with because, as in example (11). Beside that, other expressions, that normally precede statements, can serve as an indicator of an RQ, such as in one way or another in example (12), or compared to... in example (13) :

(10) ALFIERI: After all, who have I dealt with in my life? Longshoremen and their wives, and fathers...

(Miller, A View from the Bridge, 316)

(11) ALFIERI: (...) The child has to grow up and go away, and the man has to learn to forget. Because after all, Eddie - what other way can it end? (...)

(Miller, A View from the Bridge, 342)

(12) HYMAN: (...) In one way or another, who isn't crazy? (...)

(Miller, Broken Glass, 499)

(13) LIUBOV: But compared to our exalted love, what is a kiss in a summerhouse?

(Stoppard, Voyage, 89)

Although such RQs do not represent any significant number of all RQs found in our corpus, in terms of RQs with specific form, introducing an RQ with lexical items incompatible with answer-eliciting questions is second most common indicator of such questions. 


\subsubsection{Questions accompanied by ridiculous answers}

While RQs are generally not meant to be answered, they are sometimes followed by answers provided by either addressers or addressees. One type of answers provided by addressers themselves, which serves to reinforce the rhetorical interpretation of the posed questions, is ridiculous answers. By providing such answers, addressers make it clear that their questions are rhetorical, as well as that the real answers to their questions are different from the ones they offered:

(14) DAVIES: (...) who do you think I am, a dog? (...)

(Pinter, The Caretaker, 14)

(15) DAVIS: (...) What do you think I am, a wild animal ? (...)

(Pinter, The Caretaker, 14)

(16) FANNY: All right, and supposing you marry that girl and a year after you meet another girl you like better - what are you going to do, get married every year? (...)

(Miller, The American Clock, 402)

As we can see from the above examples, even outside the context it is obvious that the offered answers cannot be accepted, as well as that these questions are rhetorical. Namely, they are equivalent to implicit statements (I am not a dog / wild animal to be treated like that. / You cannot get married every now and then.). While such answers are usually attached to a question, they can also be embedded in it, as shown in example (17):

(17) CHANCE: (...) Hey, Stuff - What d'ya have to do, stand on your head to get a drink around here? (...)

(Williams, Sweet Bird of Youth, 211)

Altogether, 17 RQs from our corpus (1.41\%) had this form, which shows that it is also very rare.

\subsubsection{Questions realized in 'why + lexical verb' form}

Questions that begin with why followed by a bare infinitive of a lexical verb have rhetorical interpretation in most cases:

(18) ALMA: How gently a failure can happen! The way that some people die, lightly, unconsciously, losing themselves with their breath ... .

JOHN: Why - why call it a failure?

(Williams, The Eccentricities of a Nightingale, 483)

(19) CHANCE: She's gone. Why talk about her?

(Williams, Sweet Bird of Youth, 160)

(20) RALPH: Don't call home, now. Why upset the old people on Christmas Eve?

(Williams, Period of Adjustment, 282) 
The obvious answer implied by the addressers in the above questions is it is pointless to do/say so. However, if we expand the questions with an auxiliary verb and subject (Why do you call it a failure?/ Why are you talking about her?) it would probably lead the addressee to understand those questions as answer-eliciting, and he/she would feel obliged to respond.

According to the results obtained in this research, 10 out of $1205 \mathrm{RQs}$ found in our corpus $(0.82 \%)$ had this form.

\subsubsection{Questions incorporated into declarative or imperative sentences}

Another form indicative of RQ is questions incorporated into declarative or imperative sentences. By inserting questions into such sentences (and thereby not giving their interlocutors any time to respond), addressers make it clear that their questions are not meant to be answered, and leave it up to the addressees to work out obvious answers implied by them:

(21) HYMAN: What about the marriage? I promise you this is strictly between us.

HARRIET: What can I tell you, the marriage is a marriage.

(Miller, Broken Glass, 518)

(22) MAX: (...) Anyway, what's the difference, you did it, you made a wonderful choice, you've got a wonderful family, a marvellous career... (...)

(Pinter, The Homecoming, 48-49)

While such RQs are usually embedded in declarative sentences, they can also be joined with imperatives, as shown in example (23):

(23) GELLBURG: I'd better be getting home. I don't know whether to ask you this or not.

HYMAN: What's to lose, go ahead.

(Miller, Broken Glass, 504)

Out of 1205 RQs found in our corpus, 11 (0.91\%) were realized in this form.

\subsubsection{Auto-responsive questions}

As noted earlier, this type of RQs is mentioned by Schmidt-Radefeldt (1977), who states that such questions already contain an answer. They are realized in the form wh-question + if not/but/(other) than + the only possible answer:

(24) LADY CROOM: So much the better - what are a friend's books for if not to be borrowed? (...)

(Stoppard, Arcadia, 34)

(25) FELICE: And you? What are you doing but clasping your hands together as if in prayer? 
(Williams, Out Cry, 794)

(26) JOWETT: (...) What better example can we show them than classical antiquity? Nowhere was the ideal of art, morality and social order realized more harmoniously than in Greece in the age of the great philosophers.

(Stoppard, The Invention of Love, 17)

In the above examples, the obvious answers (the only purpose of a friend's books is to be borrowed; the only thing you do is clasping your hands; the best example we can show is classical antiquity) are integrated into questions.

The word order of such questions can be changed, so that the incorporated answer follows right after the wh-word (+else), as shown in the following example:

(27) RALPH: (...) Who else but a sucker like me, Ralph Bates, would have married a girl with no looks, a plain, homely girl that probably no one but me had ever felt anything but just - sorry for!

(Williams, Period of Adjustment, 312)

Similar to other above-mentioned specific forms typical of RQs, this form is not common either, since we identified only 14 such RQs (1.16\%).

\subsection{Semantic indicators that a question is rhetorical}

Out of all specific forms which indicate that a question is rhetorical, the single most common one is what we term as semantic incompatibility. Namely, in such RQs, the addresser combines concepts that are mutually exclusive, thereby ensuring that his/her question is understood as rhetorical:

(28) MINER: I am a coal miner, Comrade Rakowski. Miners are going to work hungry - how can you expect hungry men to raise production?

(Stoppard, Squaring the Circle, 244)

As we can see in the above example, the concept of hungry workers is combined with the concept of raising production. Since these concepts seem contradictory, this automatically leads the addressee to interpret the question as rhetorical, i.e. as an indirect statement (It is impossible for hungry workers to raise production.).

Similarly, rhetorical interpretation of the questions in the following examples is ensured by juxtaposing mutually incompatible concepts:

(29) DAVIES: How can I cut a loaf of bread without no knife?

(Pinter, The Caretaker, 58)

(30) ALFIERI: What are you going to do?

EDDIE: What can I do? I'm a patsy, what can a patsy do? I worked like a dog twenty years so a punk could have her, so that's what I done. (...)

(Miller, A View from the Bridge, 342-343)

Any competent speaker knows that in order to cut bread you need a knife, or that a patsy is someone who is incapable of doing much. While it would still be 
possible to construe a context in which such questions are used as answereliciting ${ }^{11}$, in most cases they will be interpreted as rhetorical.

RQs that include semantic incompatibility are sometimes formed in such a way that the addresser asks about the benefit of something that is apparently useless, as shown in the following examples:

(31) MAX: (...) Listen, what's the use of beating around the bush? That woman was the backbone to this family.

(Pinter, The Homecoming, 46)

(32) GELLBURG: Say, you're not blaming this on me, are you?

HYMAN: What's the good of blame? (...)

(Miller, Broken Glass, 505)

(33) CHICKEN: Floods make the land richer.

MYRTLE: What good does that do if you drown?

(Williams, Kingdom of Earth, 676)

No matter what the context is, it is hard to see any benefit in beating around the bush, blaming someone, or drowning, so such questions will almost invariably be understood as rhetorical.

Futhermore, such RQs often include asking addressees if they want or find appealing something unpleasant:

(34) RALPH: Susie, don't go in my kitchen. You want to be arrested for trespassing, Susie?

(Williams, Period of Adjustment, 305)

(35) HYMAN: You should already be having therapy to keep up your circulation. You have a long life ahead of you, you don't want to live it in a wheelchair, do you? (...)

(Miller, Broken Glass, 544)

(36) RICHARD: Do you think it's pleasant to know that your wife is unfaithful to you two or three times a week, with great regularity?

(Pinter, The Lover, 34-35)

Whatever the context, going to jail, spending a life in a wheelchair, or having a wife who cheats on you are not the things that anybody wishes for, so such questions leave room for only one possible answer.

As for RQs with a specific form that facilitates their rhetorical interpretation, semantic incompatibility is by far the most common indicator of such questions. Namely, 87 out of 1205 RQs identified in this study $(7.21 \%)$ included it.

\footnotetext{
${ }^{11}$ For instance, if we imagine an innovator who comes up with a way to cut bread with something else other than knife, then the question in (27) could be interpreted as answer-eliciting.
} 


\subsection{Overview of frequency of occurrence for specific forms in which RQs are realized}

The frequency of occurrence for all the specific forms elaborated above is shown in Figure 2 below:

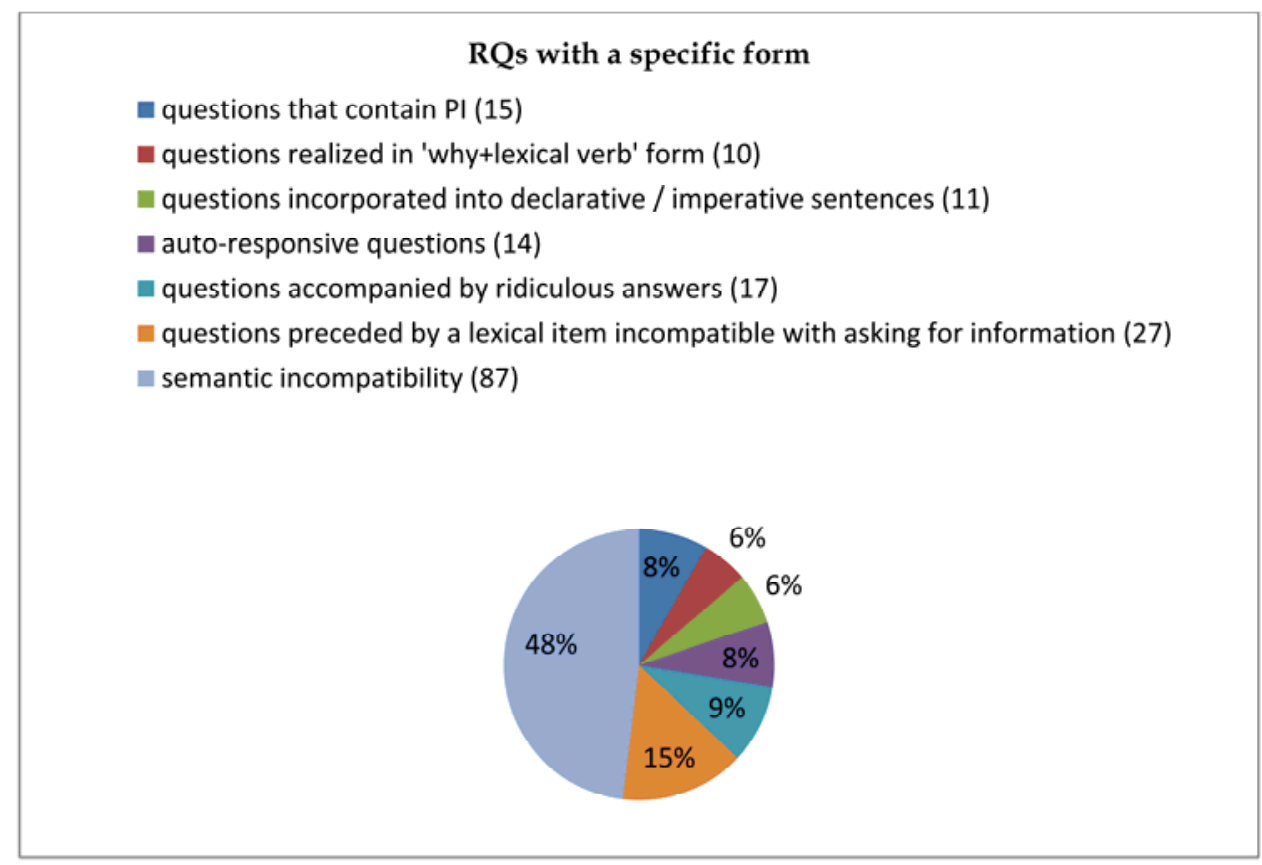

Figure 2: Frequency of specific forms in which RQs are realized

\section{Conclusion}

Based on the results obtained in this research, we can conclude that in most cases $(85 \%)$ rhetorical and standard questions have the same form, and whether they will be interpreted as rhetorical or answer-eliciting depends entirely on the context in which they are used.

However, we identified seven patterns that are indicative of RQs, so questions that follow one of those patterns are rhetorical in most contexts. For the sake of clarity, we classified them under the category of syntactic or semantic indicators of RQs. Altogether, $15 \%$ of the RQs found in our corpus had one of those forms.

The use of polarity items in questions, and lexical items (whether a single word or an expression) that normally precede statements in front of questions are among 
syntactic indicators that those questions are rhetorical. Furthermore, questions with attached ridiculous (and obviously unacceptable) answers, questions incorporated into declarative or imperative sentences, questions realized in the form 'why + lexical verb', as well as so-called auto responsive questions (those that already contain the only possible answer) are all typically rhetorical.

However, the most common form indicative of RQs is what we call semantic incompatibility. This basically refers to combining conflicting concepts in a question, thereby indicating that the question is rhetorical.

In closing, although in most cases there are no formal differences between rhetorical and answer-eliciting questions, some RQs do have a specific form that differentiates them from standard questions.

\section{References}

Athanasiadou, Angeliki (1991). The discourse function of questions. Pragmatics: 1.1: 107-122. Brown, Penelope, Steven C. Levinson (1987). Politeness. Some Universals in Language Usage. Cambridge: Cambridge University Press.

Frank, Jane (1990). You call that a rhetorical question? Forms and functions of rhetorical questions in conversation. Journal of Pragmatics 14: 723-738.

Gergen, David (2001). Eyewitness to Power: The Essence of Leadership Nixon to Clinton. New York: Simon and Schuster.

Han, Chung-hye (2002). Interpreting interrogatives as rhetorical questions. Lingua 112: 201229

Jung, Verena, Angela Schrott (2003). A question of time? Question types and speech act shifts from a historical-contrastive perspective: some examples from Old Spanish and Middle English. Jasczolt, Katarzyna M., Ken Turner eds. Meaning Through Language Contrast. Amsterdam: John Benjamins, 345 - 371.

Ilie, Cornelia (1994) What Else Can I Tell You? A Pragmatic Study of English Rhetorical Questions as Discursive and Argumentative Acts. Stockholm: Almqvist \& Wiksell International.

Sadock, Jerrold M. (1974) Toward a Linguistic Theory of Speech Acts. New York: Academic Press.

Schaffer, Deborah (2005). Can rhetorical questions function as retorts? Is the Pope Catholic? Journal of Pragmatics 37: 433-460.

Schmidt-Radefeldt, Jürgen (1977). On so called 'rhetorical' questions. Journal of Pragmatics 1: 375-392.

Zwarts, Frans (1996). A hierarchy of negative expressions. In Heinrich Wansing ed. Negation: A notion in focus. Berlin: Walter de Gruyter , 169-194.

\section{Corpus}

Miller, A.: A View from the Bridge (1955) (The Forms of Drama, Houghton Mifflin Company, 1972); Death of a Salesman (1949); After the Fall (1964); The American Clock (1980); The 
Last Yankee (1993); Broken Glass (1994) (The Portable Arthur Miller, Bigsby C., Penguin Group, 2003).

Pinter, H.: The Dumb Waiter (1957); The Caretaker (1959) (The Caretaker and The Dumb Waiter: Two Plays, Grove Press, 1988); The Birthday Party (1957) (The Birthday Party and The Room: Two Plays, Grove Press, 1961); The Hothouse (1958) (The Hothouse, Grove Press, 1999); The Lover (1962) (The Lover, Tea Party, The Basement: Two Plays and a Film Script, Grove Press, 1967); The Homecoming (1964) (The Homecoming, Grove Press, 1966); Betrayal (1978) (Betrayal, Grove Press, 1979).

Stoppard, T.: The Real Inspector Hound (1968); Dirty Linen (1976) (The Real Inspector Hound and Other Plays, Grove Press, 1998); Squaring the Circle (1984) (Tom Stoppard: Plays 3, Faber and Faber, 1998); Arcadia (1993) (Arcadia, Faber and Faber, 1993, fifth printing 2000); The Invention of Love (1997) (The Invention of Love, Grove Press, second edition, 1998); Voyage (2002) (Voyage: The Coast of Utopia Play 1, Faber and Faber, 2002).

Williams, T.: Orpheus Descending (1957); Suddenly Last Summer (1958); Sweet Bird of Youth (1959); Period of Adjustment (1960); The Mutilated (1966); Kingdom of Earth (1968); Out Cry (1971); Small Craft Warnings (1972); The Eccentricities of a Nightingale (1976); Vieux Carre (1977); A Lovely Sunday for Creve Coeur (1979) (Tennessee Williams: Plays 19571980, The Library of America, New York, 2000).

Author's address:

Vrapčići 76, 88000 Mostar

Bosnia and Herzegovina

E-mail: dzemal.spago@unmo.ba

Received: August 30, 2017

Accepted for publication: November 3, 2017 